\title{
Environmental Control and Life Support Integration Strategy for 6-Crew Operations
}

\author{
Stephanie M. Duchesne ${ }^{1}$ \\ Wyle Integrated Sciences and Engineering, Houston, TX, $77 X X X$ \\ Chad H. Tressler ${ }^{2}$ \\ Booz Allen Hamilton, Houston, TX, 77058, USA
}

\begin{abstract}
The International Space Station (ISS) crew complement has increased in size from 3 to 6 crew members. In order to support this increase in crew on ISS, the United States on-orbit Segment (USOS) has been outfitted with a suite of regenerative Environmental Control and Life Support (ECLS) hardware including an Oxygen Generation System (OGS), Waste and Hygiene Compartment (WHC), and a Water Recovery System (WRS). The WRS includes the Urine Processor Assembly (UPA) and the Water Processor Assembly (WPA). With this additional life support hardware, the ISS has achieved full redundancy in its on-orbit life support system between the USOS and Russian Segment (RS). The additional redundancy created by the Regenerative ECLS hardware creates the opportunity for independent support capabilities between segments, and for the first time since the start of ISS, the necessity to revise Life Support strategy agreements. Independent operating strategies coupled with the loss of the Space Shuttle supply and return capabilities in 2010 offer new and unique challenges. This paper will discuss the evolution of the ISS Life Support hardware strategy in support of 6-Crew on ISS, as well as the continued work that is necessary to ensure the support of crew and ISS Program objectives through the life of station.
\end{abstract}

\section{Nomenclature}

$\begin{array}{ll}A C Y & =\text { Waste Collection System } \\ A T V & =\text { Ariane Transport Vehicle } \\ \text { БЖ } & =\text { Elektron-VM Liquid Unit } \\ C C A A & =\text { Common Cabin Air Assembly } \\ C D R A & =\text { Carbon Dioxide Removal Assembly } \\ C K B & =\text { Russian Air Conditioner } \\ C O_{2} & =\text { Carbon Dioxide } \\ C O T S & =\text { Commercial Orbital Transportation Services } \\ C P B \text { K2M } & =\text { Russian Water Processor } \\ C R S & =\text { Commercial Resupply Services } \\ C W C & =\text { Contingency Water Container } \\ D C-1 & =\text { Docking Compartment-1 } \\ \text { ECLS } & =\text { Environmental Control Life Support } \\ \text { EДB } & =\text { Russian Water Bag } \\ \text { EДB-y } & =\text { Russian Urine Storage Tank } \\ \text { ELC-3 } & =\text { Express Logistics Carrier 3 } \\ \text { Elektron-VM } & =\text { Russian Oxygen Generator } \\ \text { ESA } & =\text { European Space Agency } \\ \text { EVA } & =\text { Extra Vehicular Activity }\end{array}$

${ }^{1}$ ISS Environmental Control and Life Support Systems Subsystem Manager, EC6 Crew and Thermal Systems Division.

${ }^{2}$ ISS Vehicle Integrated Performance Environments and Resources Water Consumables Lead, OM3 Vehicle Integrated Performance Evaluation Resources Team 


$\begin{array}{ll}F G B & =\text { Functional Cargo Block } \\ H T V & =\text { H-II Transfer Vehicle } \\ I S S & =\text { International Space Station } \\ J A X A & =\text { Japan Aerospace Exploration Agency } \\ J E M & =\text { Japanese Experiment Module } \\ M R M 2 & =\text { Mini research Module } 2 \\ K T O & =\text { Russian Solid Waste Container } \\ k g & =\text { Kilograms } \\ \text { L } & =\text { Liter } \\ \text { lbm } & =\text { Pounds mass } \\ \text { LiOH } & =\text { Lithium Hydroxide } \\ m L & =\text { Milliliter } \\ m m H g & =\text { Millimeters of Mercury } \\ N A S A & =\text { National Aeronautics and Space Administration } \\ O_{2} & =\text { Oxygen } \\ O G S & =\text { Oxygen Generation Systems } \\ P 3 & =\text { Port } 3 \\ p p C O_{2} & =\text { partial pressure carbon dioxide } \\ p p N_{2} & =\text { partial pressure nitrogen } \\ p p O_{2} & =\text { partial pressure oxygen } \\ S F O G & =\text { Solid Fuel Oxygen Generator } \\ S M & =\text { Service Module } \\ \text { std } & =\text { standard } \\ U L F-3 & =\text { Utilization Logistics Flight-3 } \\ U S O S & =\text { United States On-orbit Segment } \\ R o d n i k & =\text { Russian Water Tank } \\ R S & =\text { Russian Segment } \\ W H C & =\text { Waste and Hygiene Compartment } \\ W P A & =\text { Water Processor Assembly } \\ W R S & =\text { Water Recovery System } \\ & \end{array}$

\section{Introduction}

$\mathrm{T}$ HE International Space Station (ISS) long duration crewmember complement increased from 3 to 6 crewmembers on May 29, 2009 with the arrival of Soyuz 19. The ability to increase the crew complement from 3 to 6-crew was largely based on the capability to increase both the capacity of the life support hardware on ISS as well as its dependence upon regenerative capabilities. The ISS environmental control and life support system is required to:

1) Provide water

2) Condition the atmosphere

3) Maintain Atmosphere

4) Control Carbon Dioxide (CO2) and other atmospheric contaminants

5) Support hygiene

In order to sustain a crew of 6 on ISS, an operational strategy must be employed that optimizes system performance across ISS, maintains a level of system redundancy, and protects for system failure and recovery.

\section{ISS Life Support: 3-Crew Support Strategy}

During the 3 Crewmember phase of ISS, life support was primarily provided by the Russian Segment (RS). ISS re-supply vehicles included the U.S. Shuttle, Russian Progress, and to a small extent, the Russian Soyuz-TIM vehicle. RS system operations were backed up by United States Orbital Segment (USOS) capabilities. Frequent resupply and return capabilities provided by the Shuttle and Progress provided ample life support for the ISS crew.

\section{A. Provide Water}


ISS water for both systems and crew was primarily provided by RS systems with back-up provided by U.S. resupply capabilities. Water regeneration was provided through the processing of condensate in the Russian water processor [CPB K2M]. Supplemental water was also provided to ISS in Russian Progress transfer vehicle tanks as well as by collection of U.S. Shuttle fuel cell water, a byproduct of shuttle power generation. ISS water was used primarily for crew consumption, systems, and hygiene. RS water was either launched in Rodnik tanks on Progress delivery vehicles and stowed in ISS Rodnik tanks or Russian water bags (EДBs) or provided for direct use from the [CPB K2M]. The 250L Rodnik tanks are used mainly for on-orbit reserves to protect for failures. The [CPB K2M] also provides water for the Russian oxygen generator (Elektron-VM). The only source of USOS water was supplied through collection of Shuttle fuel cell water that was transferred into Contingency Water Containers (CWCs) for stowage on ISS.

The water usage planning rates used for the 3 -crew assembly stage of ISS are $0.5 \mathrm{~L} /$ person/day for potable water and $1.5 \mathrm{~L} /$ person/day for technical water. The total re-supply rate was therefore $2 \mathrm{~L} /$ person/day. These rates were based on the daily water balance for an individual crew member as shown in Figl ${ }^{3}$. $2.85 \mathrm{~L}$ of water was nonrecoverable through oxygen production, trash, and crew waste collection. As the RS systems were the only systems utilized for supply of water to the crew, maintaining the balance of contributions data involved only the tracking of water provided by re-supply vehicles.

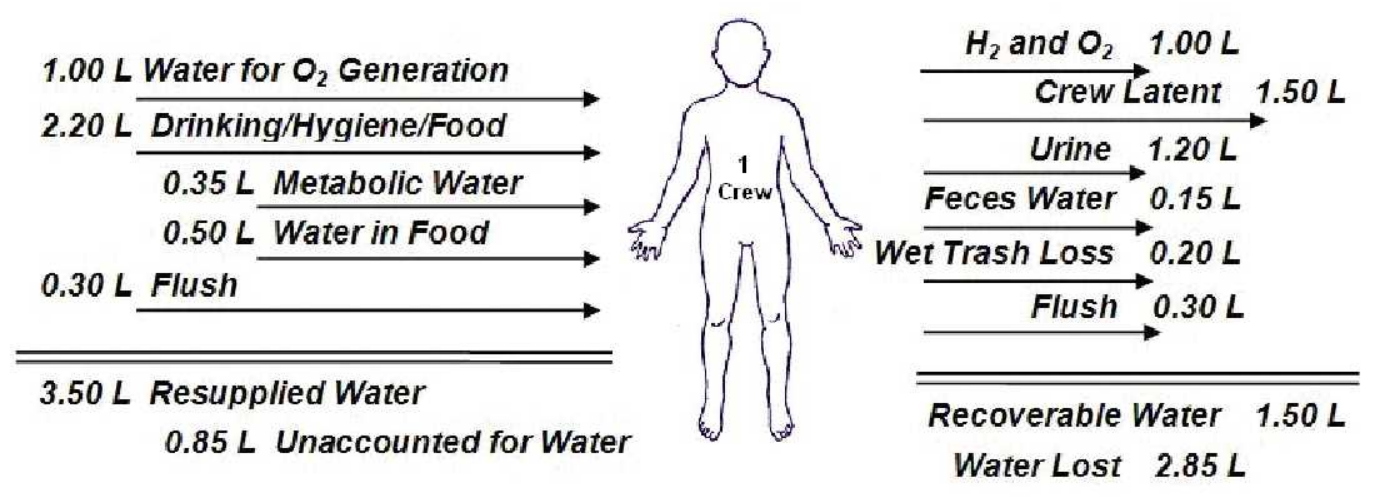

Figure 1. Crewmember Daily Water Balance in Assembly Stage

\section{B. Condition Atmosphere}

Both the RS [CKB] air conditioner and the USOS Common Cabin Air Assemblies (CCAA) condensing heat exchangers provided humidity and temperature control on ISS. The RS contained two [CKB] systems, and the USOS was equipped with a CCAA in each module, with two in the larger modules. ISS condensate was mainly collected in the Russian [CKB] air conditioner through control of atmospheric dew points. Though there are two on orbit, each [CKB] unit is operated individually. It was more advantageous to collect condensate on the RS since the condensate was fed directly to the Russian water processor [CPB K2M] for reclamation. Additional condensate that was collected when necessary by the CCAA was bagged in CWCs and carried to the [CPB K2M] for processing. Transferring condensate in CWCs for processing on the RS was cumbersome and required ample crew time, so condensate collection on the USOS was avoided if possible. The [CKB] was capable of collecting a three crew condensate load of $4.5 \mathrm{~L}$ of condensate per day when a dew point of $10-12{ }^{\circ} \mathrm{C}$ was maintained on the ISS RS and the USOS was not collecting condensate ${ }^{3}$.

\section{Maintain Atmosphere}

ISS total pressure control was maintained in order to support the proper total pressure, oxygen partial pressure $\left(\mathrm{ppO}_{2}\right)$, and nitrogen partial pressure $\left(\mathrm{ppN}_{2}\right)$ to support human habitability requirements for the ISS crew. ISS atmosphere was lost through vehicle dockings, Extra Vehicular Activities (EVA), structural leakage, and system venting.

The RS was primarily responsible for metabolic oxygen which is provided through water electrolysis using the Elektron-VM. Elektron-VM was supplemented by Progress vehicle oxygen tanks, Shuttle vehicle oxygen transfers/represses, Solid Fuel Oxygen Generators (SFOG), and 2 USOS external high pressure oxygen tanks located external to the Joint Airlock. Each crewmember required approximately $0.8346-0.86 \mathrm{~kg}$ per day of $\mathrm{O}_{2}{ }^{3}$. The Elektron-VM used product water from the [CPB K2M] to introduce oxygen to the ISS cabin. The Elektron-VM was capable of producing oxygen for a crew of 2 to 6 people and was operated until system failure ${ }^{4}$. The Russian Progress vehicle was capable of providing a maximum of $42-50 \mathrm{~kg}$ of oxygen. The SFOG oxygen candles produced 
$1.29-1.84 \mathrm{~kg}$ of $\mathrm{O} 2$ depending on the model. The external oxygen tanks were recharged by the Shuttle, and had a total capacity of $387.2 \mathrm{~kg}$.

Nitrogen was introduced into the ISS atmosphere primarily using Progress air tanks, Shuttle transfers/represses, and USOS external high pressure nitrogen tanks. ISS atmosphere resupply was maintained primarily by visiting vehicles, as the high pressure external tanks were typically reserved for EVAs and systems. The Progress could provide a maximum of 38.6-48.6 kg of air. The external nitrogen tanks were refilled by equalizing between the ISS and shuttle, with a total capacity of $172.1 \mathrm{~kg}$.

Air loss due to structural leakages and systems losses was calculated based on ISS estimated nitrogen gas loss trends over time. This calculation was routinely performed in order to establish an adequate gas re-supply strategy. A key assumption made in this calculation was that the ISS atmosphere is composed of only nitrogen and oxygen. This assumption was reasonable in that the percentage of other trace gases on-orbit was very low. The total calculated average daily cabin air mass loss rate for the dates from October 2004 to October 2007 was $-0.0856 \mathrm{~kg}$ per day. Fig.2 shows a box plot and scatter graph of the average quarterly ISS air leakage rates from Fiscal Year 2005 to Fiscal Year $2007^{3}$.
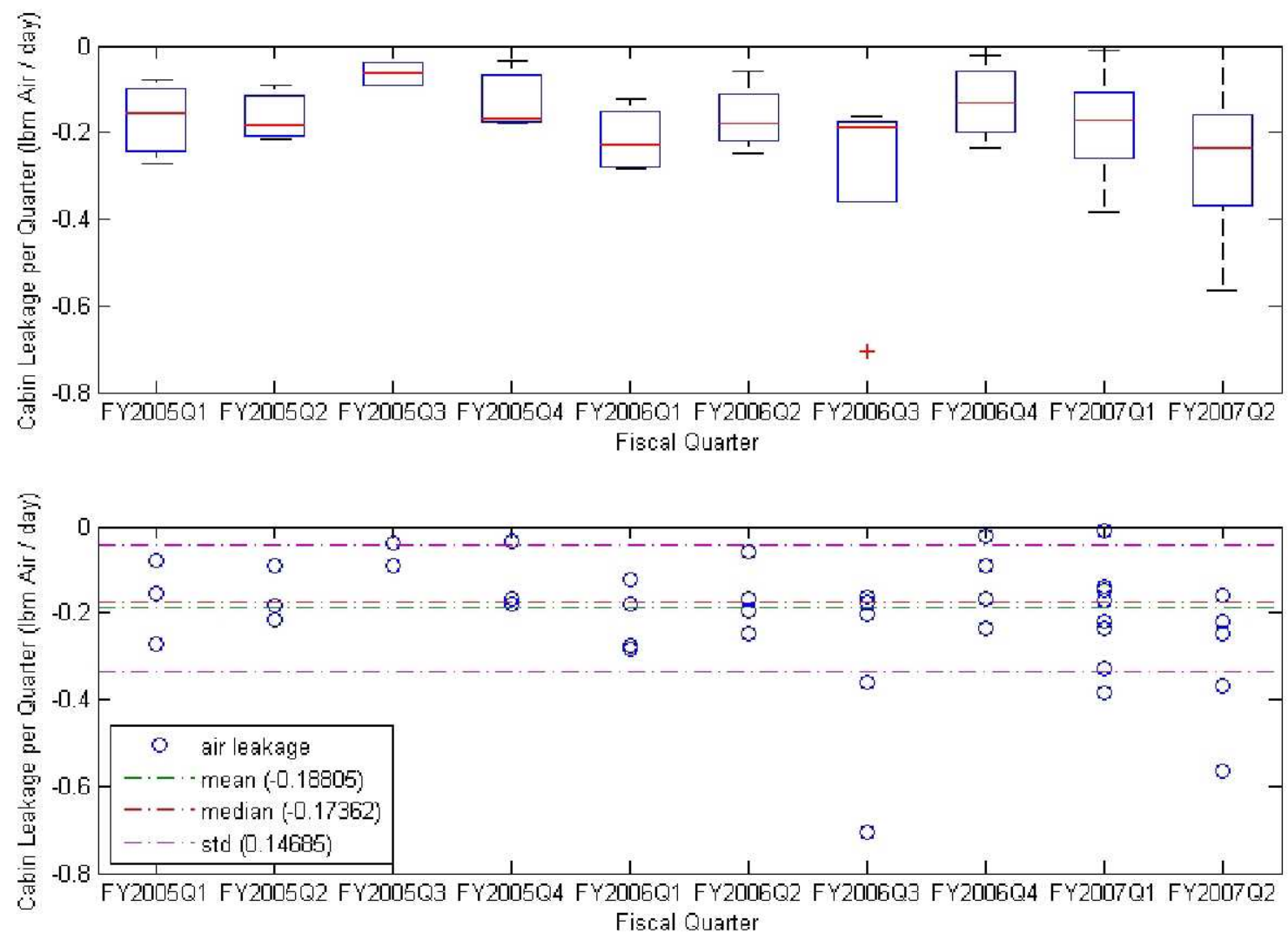

Figure 2. ISS air leakage rate per quarter from FY2005 to FY2009.

\section{Control Carbon Dioxide}

During the assembly stage, Carbon Dioxide $\left(\mathrm{CO}_{2}\right)$ Removal was primarily provided by the RS Vozdukh and supplemented by the USOS Carbon Dioxide Removal Assembly (CDRA) and joint stores of Lithium Hydroxide ( $\mathrm{LiOH})$ carbon dioxide absorbent canisters. The Vozdukh system was designed to provide carbon dioxide removal for approximately 5 crewmembers using its 3 adsorbent cartridges in order to maintain an acceptable partial pressure of carbon dioxide $\left(\mathrm{ppCO}_{2}\right)$. The Vozdukh system operated on $\mathrm{CO}_{2}$ adsorption and desorption to space vacuum. The Vozdukh experienced a failure in one of its adsorbent beds shortly after start-up and was only able to remove $\mathrm{CO}_{2}$ at about a 3 crew capacity. The U.S CDRA similarly removed $\mathrm{CO}_{2}$ using adsorption/desorption cycles with its 2 adsorbent beds. In single bed mode, the CDRA could remove $\mathrm{CO}_{2}$ for up to 3 crewmembers and up to 7 crewmembers in dual bed mode. During the 3-crew timeframe, the CDRA acted as a back-up system to Vozdukh.

\section{E. Support Hygiene}


The RS housed the only waste collection system [ACY] on ISS. The [ACY] collected both urine and fecal matter and stored it until it is necessary to dispose of it. The [ACY] used $50 \mathrm{~mL}$ of flush water as well as preservative for each urination and stowed this in a replaceable Russian urine storage tank (ЕДВ-У). Тhe ЕДВ-У had a $22 \mathrm{~L}$ capacity. For an average crew of 3, ЕДВ-У change outs were required every 4-5 days. Solid waste was collected in the Russian solid waste container [KTO]. Urine was disposed of on the Russian Progress vehicle either via transfer into Progress tanks or if necessary, in the ЕДВ-У itself. [КТО] were disposed of on Progress vehicles. There was no capability to reclaim the water used during waste collection.

There was no specified location on ISS designated for Hygiene activities. Crewmembers performed hygiene activities in a convenient location on ISS using hygiene items provided such as dry shampoo and moistened towels. Usage of free water during hygiene activities was prohibited in order to protect ISS structures and hardware. Water utilized by crew for personal hygiene was collected by the RS condensate collection system [CKB] or the USOS Common Cabin Air Assemblies (CCAA) and processed in the [CPB K2M].

\section{ISS 6-Crew Life Support Strategy}

In the 6 Crewmember phase of ISS, the RS no longer is prime for life support, and both the RS and USOS are required to support their own crew load. For the timeframe being addressed, the USOS includes the U.S. core modules (Node 1, Lab, Airlock, Node 2 and Node 3) as well as ESA's Columbus module and JAXA's Japanese Experiment Module (JEM). The Russian segment consists of the Functional Cargo Block (FGB), Service Module(SM), and Docking Compartment-1 (DC-1), and Mini research Module 2 (MRM 2). In order to meet the life support load of an additional 3 crewmembers on ISS as well as contractual requirements, a suite of USOS regenerative life support hardware is necessary. The USOS regenerative life support hardware includes a Water Recovery System (WRS), Oxygen Generation System (OGS), and Waste and Hygiene Compartment (WHC). Along with the development of these new systems, it is also necessary to take into account the strategy for re-supply and on-orbit maintenance. The U.S. Shuttle is set to retire in late 2010 or early 2011 , leaving the ISS without its largest resupply vehicle and its only vehicle currently capable of returning cargo. During the post-shuttle retirement timeframe, the ISS will be re-supplied by the Russian Progress, European Ariane Transport Vehicle (ATV), the Japanese H-II Transfer Vehicle (HTV), and eventually Commercial Orbital Transportation Services (COTS) vehicles. Given the limited return capability and small cargo supply capability on ISS, it is imperative that ISS life support move closer towards the ideal of a closed-loop system.

\section{F. Provide Water}

In order to improve the amount of recoverable water on ISS as well as create system redundancy, NASA augmented the USOS with the WRS. The WRS is comprised of a Urine Processor Assembly (UPA) and a Water Processor Assembly (WPA). The UPA is fed urine and flush water directly from the USOS WHC and processes it into purified water. The UPA is also capable of processing urine and flush water transferred in an ЕДВ-У from the Russian [ACY]. The WPA is fed UPA distillate, condensate from the CCAAs, and system waste water, and processes it into iodinated water. This iodinated water is delivered through a potable water bus to the OGS for oxygen generation, the Potable Water Dispenser (PWD) for crew consumption, and other systems and payloads as necessary. With the addition of the USOS water recovery system, it is possible to process $3.00 \mathrm{~L}$ of water per crewmember as shown in Fig. $3^{3}$, significantly decreasing ISS water resupply needs by providing $\sim 2.5 \mathrm{~L}$ of recovered water ${ }^{3}$.

The capability to recover water on ISS becomes even more important during the 6-crew timeframe when Shuttle retires and the USOS loses a significant water re-supply capability. In order to protect for failures with the UPA and WPA systems, water transfer from shuttle fuel cell water will be maximized until shuttle retirement in order to create a water stockpile. In addition to the CWC stockpile, the ATV and Progress are capable of carrying water in tanks to ISS and HTV and eventually the COTS vehicles are capable of launching full CWCs. As both sides now have regenerative capability as well as the means to provide water to support the crew, it is now necessary to track actual consumption of water along with all deliveries to maintain balance of contributions. 


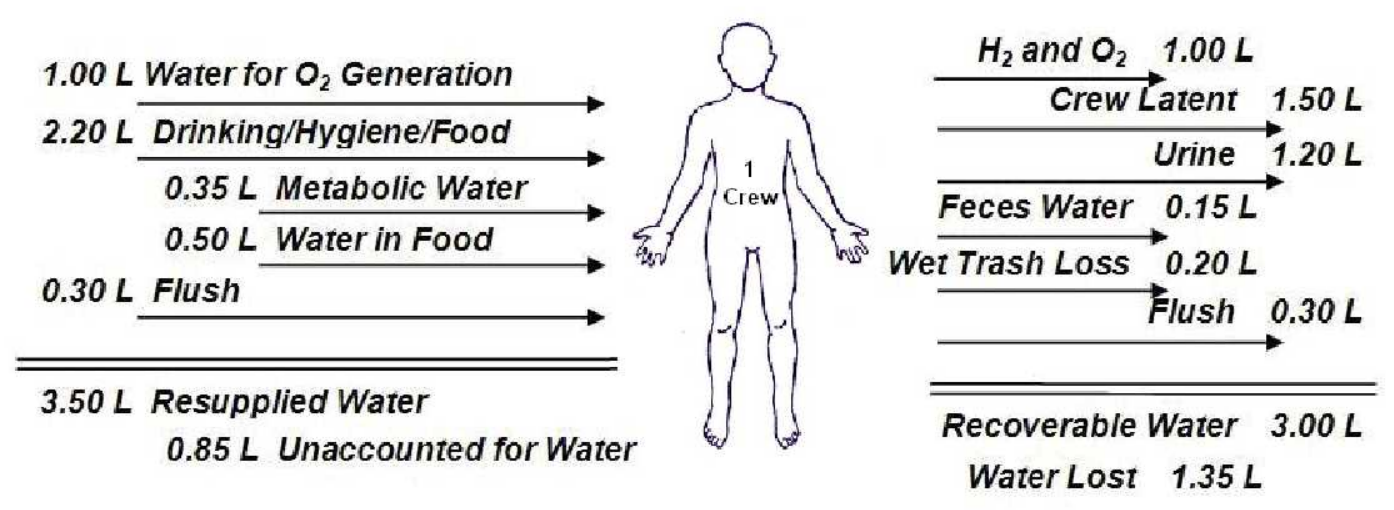

Figure 3. Crewmember Daily Water Balance with U.S. Water Recovery System

\section{G. Condition Atmosphere}

At Assembly Complete, both the RS and USOS actively control humidity and temperature on ISS. Due to the arrival of the USOS WRS, it is no longer necessary to drive ISS condensate towards the RS by controlling dew points. With the increased size of the USOS and the large number of CCAAs, it is estimated that the USOS will collect a higher quantity of condensate than the RS. Even though the USOS is more likely to collect condensate, the overall clean water balance is maintained based on the ISS crew complement on each segment by transferring water between segments, modifying consumption of water for oxygen production, and shifting consumption by crew for drinking water between segments, as well as other means.

\section{H. Maintain Atmosphere}

At Assembly complete, ISS atmosphere is supported equally by both the RS and USOS. The RS $\mathrm{O}_{2}$ support strategy remains largely unchanged, with the Elektron-VM continuing to support a 3-crew load. The Elektron-VM БЖ Liquid Unit is certified for 1 year of operations however the current unit has been in operation for over 2 years ${ }^{4}$. Due to the operational strategy of using the system until failure, the Elektron-VM system is not capable of supporting a full 6 crewmembers. RS supplemental oxygen is provided by Progress vehicle oxygen tanks and Russian Solid Fuel Oxygen Generators. The USOS metabolic oxygen support strategy is based primarily on the use of the OGS. The OGS is a water electrolysis device similar to the Elektron-VM which uses processed water from the WPA to generate oxygen. The OGS can support up to an 11 crewmember load. As during the 3 -crew phase, the USOS also maintains 3 high pressure oxygen tanks external to the joint airlock as back-up support to the OGS and to support EVA and other high pressure $\mathrm{O} 2$ users. 1 additional external high pressure oxygen tank will be launched to ISS on shuttle flight ULF-5 in late 2010 and stowed on the external Express Logistics Carrier 3(ELC-3) located on the Port 3(P3) Truss. The ATV also contains 3 gas tanks and is capable of transporting up to $100 \mathrm{~kg}$ of gas (air, nitrogen, oxygen) with a maximum of 2 gases per flight.

As with Oxygen supply, Nitrogen introduction is a shared responsibility between the RS and USOS. However at assembly complete, the USOS will make up about $70 \%$ of the ISS total volume. Based on structural leakage alone, it can be assumed that the USOS, having the largest volume, is responsible for a larger portion of ISS atmosphere replenishment. At Assembly Complete, ISS atmosphere is replenished using Russian Progress air tanks, Shuttle transfers/represses through shuttle retirement, ATV gas tanks, and USOS external high pressure nitrogen tanks.

ISS structural and system nitrogen gas loss trends analyzed from July 2008 to November 2008 showed an air mass loss rate of $-0.195 \mathrm{~kg}(-0.43 \mathrm{lbm})^{3}$. This is a significant increase from the trending data from October 2004 to October 2007 however not surprising considering that Node 2 was added in late October of 2007, ESA's Columbus module was added in February of 2008, and JAXA's JEM elements were added from March to May of 2008. Based on this trending data, ISS air resupply planning for the 6-crew timeframe is set to $-0.23 \mathrm{~kg}(-0.5 \mathrm{lbm})^{3}$ of air per day in anticipation of the arrival of additional ISS modules and systems. Figure $4^{3}$, ISS Air Leakage per Quarter from FY2005 to FY2009, shows a box plot and scatter graph of the average quarterly ISS air leakage rates from Fiscal Year 2005 to Fiscal Year 2009. 

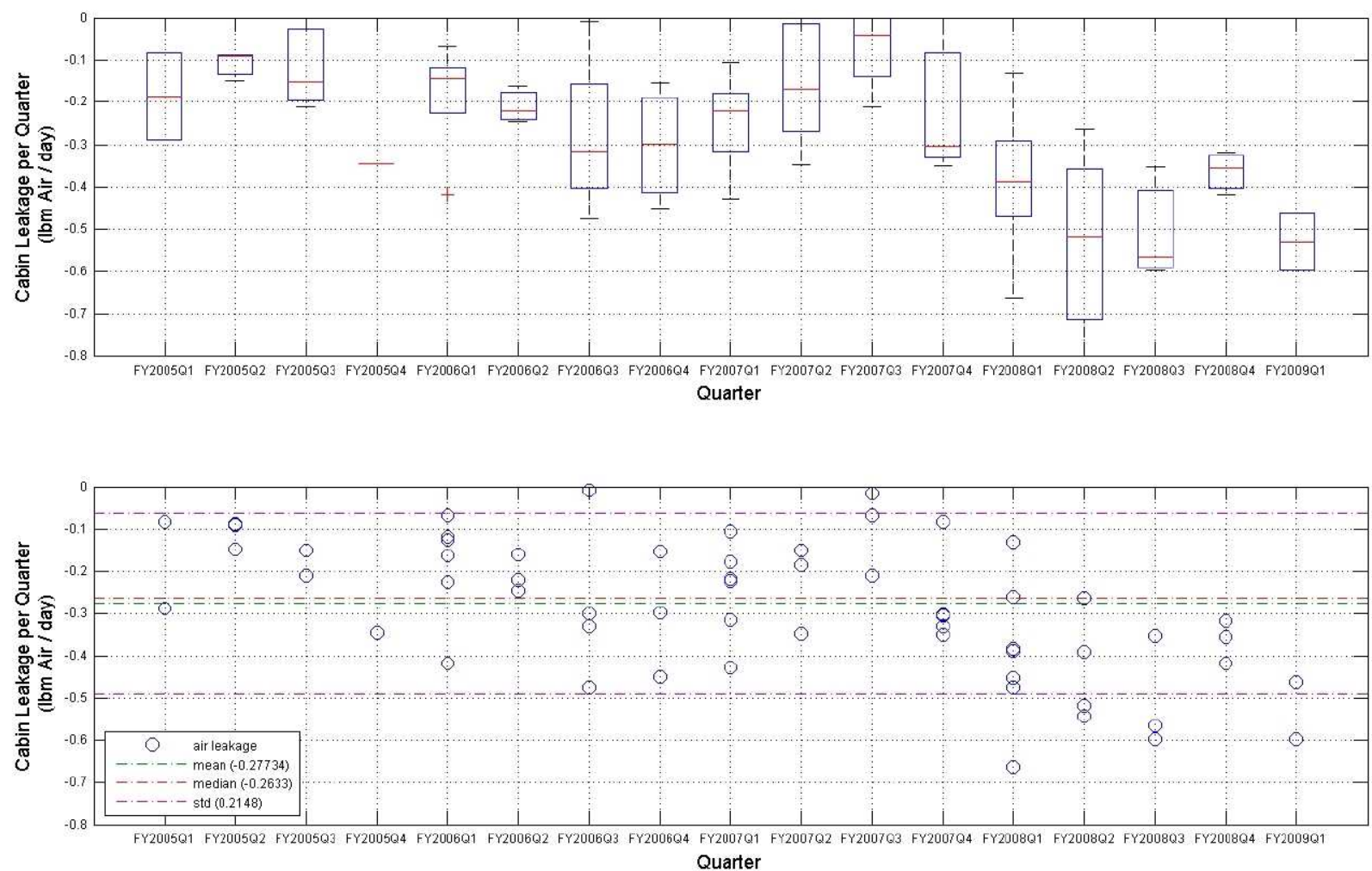

Figure 4. ISS air leakage rate per quarter from FY2005 to FY2009.

\section{Control Carbon Dioxide}

At Assembly complete $\mathrm{CO}_{2}$ Removal is shared between the RS and USOS using primarily the Vozdukh and CDRA. A second CDRA was launched on shuttle flight 17A and installed in Node3 in early 2010. The Russian Vozdukh operations remain the same as in the 3-crew timeframe with the unit removing up to a 3 crew capacity at higher ppCO2 levels. The strategy for USOS $\mathrm{CO}_{2}$ Removal is to use only one of the 2 on-orbit CDRAs at a time. With the CDRA's capability to remove a $7 \mathrm{crew}$ load of $\mathrm{CO}_{2}$, a single system is sufficient to control $\mathrm{CO}_{2}$ for the full ISS crew if needed. $\mathrm{LiOH}$ remains the back-up ppCO2 removal system on ISS, however; with the addition of a $2^{\text {nd }}$ CDRA, the ISS is decreasing its dependence on $\mathrm{LiOH}$.

\section{J. Support Hygiene}

In order to increase the crew size on ISS, an additional waste collection system to the Russian [ACY] was necessary. The USOS selected a waste collection system containing a Russian [ACY] as well as a much needed area for hygiene. The USOS WHC also has the capability of feeding pretreated urine and flush water directly to the UPA for processing or to an ЕДВ-У for storage if necessary. With the arrival of the WHC, the crew also gains a location for hygiene activities. With the WHC hygiene covers in place, the crew is allowed to use modest amounts of free water without concern of damaging ISS systems or creating problems with mold and fungus on the aging ISS.

\section{Difference between U.S. and Russian Life Support}

\section{K. Failure Support Strategy on ISS}

The ISS Life Support reserve strategy relies mainly on the capability to repair failed hardware with on-orbit spares, or replace the failed hardware on an upcoming resupply vehicle. In the 6-crew timeframe life support strategy is highly resilient in that each segment carries a full suite of life-support hardware. Most of the ISS hardware is designed to be capable of supporting up to 6-crewmembers, therefore if there is a failure of one segment's system, the strategy is that the other segments system will function as a back-up and supply the additional support. This back-up strategy would allow ISS to continue to function on minimal stowed resources. 
Unfortunately this strategy does not work for all cases. The RS life support systems have a long operational history but are old and prone to life limited failures. The USOS hardware is new with limited failure history data, and in the case of the UPA, new technology to ISS. The USOS hardware is designed to support at minimum a crew of 6-crew and is therefore well considered to assist in RS system failures; however, the hardware does not carry an operational pedigree and therefore carries a set of unknown failure risks. Providing a failure support strategy for this unique suite of life support hardware requires flexibility, a smart set of on-orbit spares, and contingency resources to support crew through hardware failures. To protect for system repairs as well as system failures, ISS consumables are held in reserve in order to sustain the ISS crew for up to 45 days. 45 days was originally defined as the amount of time it would take for Russia to prepare and launch a Progress vehicle to ISS for re-supply, and is now considered to be a conservative estimate on the time to isolate and troubleshoot problems utilizing on-board spare hardware.

\section{ISS Resupply at Assembly Complete}

Though the ISS is losing a large re-supply and return capability with the retirement of the shuttle, the ISS visiting vehicle traffic and re-supply frequency is being greatly increased due to contributions from both ISS partner support and Commercial Resupply Services (CRS). The ATV vehicle had its first successful mission to ISS in spring of 2008. The ATV is capable of re-supplying both water stores and re-pressurization gas. The ATV can remain docked to ISS for approximately 6 months, allowing ample opportunity to utilize its consumables. ATV is planned to be launched about once per year. The first HTV ISS mission was in the fall of 2009, with HTV-1. An HTV remains docked to ISS for approximately 1 month and is capable of re-supplying water in filled CWCs and ISS cargo. CRS vehicles are being manufactured by SpaceX and Orbital Sciences, with the intent of flying multiple missions each year. The first CRS mission is currently scheduled for May 2011. The SpaceX Dragon cargo vehicle is being designed to provide re-supply capability to ISS as well as return capability. The Orbital Cygnus cargo vehicle is currently designed to provide re-supply capabilities to ISS. With this large increase in visiting vehicles, the time between the arrival of a resupply vehicle becomes very short. Though significantly size limited as compared to the Shuttle, the visiting vehicle frequency should allow for quick delivery of hardware replacements and resources to ISS.

\section{Conclusion}

ISS Life Support capabilities in the 6-Crew timeframe have moved closer to the ideal of a closed loop system. Both the RS and USOS life support systems are largely complimentary and provide much needed redundancy for ISS failure support. However, by increasing the size of the supported crew, the consumption of resources in the event of failures has been accelerated, placing an increased need on rapid trouble-shooting of failures. These challenges are not wholly different than what has been seen throughout the life of ISS. Despite rigorous analysis, design and ground testing, it is impossible to know exactly how hardware will perform through launch, installation, and operation in microgravity on ISS. A large part of the life support strategy during the Assembly Phase was reliance on the capability to return large pieces of hardware for ground testing, repair, and return to ISS. It is more important now, in the Assembly Complete Phase, that ISS life support strategy take into account the risks of both old and new systems on ISS and plan for the risks ahead of time. The dissimilarity and redundancy of life support systems on both segments of the ISS, coupled with a robust sparing plan and cross segment support between international partners, reduces much of the risk involved in life support planning and ensures continued success in ISS life support.

\section{References}

\footnotetext{
3 “Joint Environmental Control and Life Support (ECLS) Functionality Strategy (JEFS)," SSP 50623, October, 2008.

${ }^{4}$ Duchesne, S. M., "Protocol: Joint Environmental Control and Life Support (ECLS) Functionality Strategy Technical Interchange Meeting (TIM)," Moscow, Russia, February 2-12, 2009.
} 